\title{
LITERATURA SURDA E PERCURSOS SÓCIO-HISTÓRICOS DE FORMAÇÃO DE DOIS PROFESSORES SURDOS
}

\section{DEAF LITERATURE AND SOCIO-HISTORICAL TRAJECTORIES IN THE DEVELOPMENT OF TWO DEAF TEACHERS}

\author{
Paula Aparecida Diniz Gomides* \\ Gilcinei Teodoro Carvalho ${ }^{* \star}$ \\ Terezinha Cristina da Costa Rocha***
}

\begin{abstract}
RESUMO
O artigo discute a formação de leitores surdos, enfocando as práticas sociais de letramento literário em que a Libras ocupa uma centralidade. Buscamos, por meio de entrevistas com dois professores surdos, de gerações diferentes, reconstruir suas trajetórias, tendo em vista, por um lado, os percursos sócio-históricos nos quais eles se engajaram, durante sua formação leitora e, por outro lado, o entendimento de constituição leitora como um fenômeno social, cultural e identitário. Estabelecemos uma articulação entre a literatura surda e a formação social e escolar de surdos, refletindo sobre os processos que lhes possibilitaram a construção de um repertório leitor e sobre as interfaces desse contexto com as políticas que reafirmaram o bilinguismo dos surdos e o direito ao uso da Libras. As experiências de socialização e de escolarização com a literatura e a língua portuguesa remetem às trajetórias da comunidade surda e, muitas vezes, revelam-se acidentadas, especialmente pela presença de processos clínico-terapêuticos de inserção na comunidade ouvinte. Contudo, as experiências relatadas também indicaram um favorecimento ao engajamento em práticas sociais de letramento literário, quer na condição de leitores que avaliam de forma contextualizada certas produções, quer na condição de autores que vivenciam performances literárias que são potencializadas pelas redes sociais que fazem circular produções representativas da comunidade surda, o que inclui o uso sistemático da Libras.
\end{abstract}

Palavras-chave: literatura surda; literatura em Libras; formação de leitores surdos; educação bilíngue; letramento literário.

\section{ABSTRACT}

The article discusses the development of readers in deaf communities, focusing on social practices of literary literacy in which Libras occupies a central role. We sought, through interviews with two deaf teachers of different generations, to reconstruct their trajectories, taking into account, on the one hand, the socio-historical paths in which they engaged during their reading education and, on the other hand, the understanding of reading constitution as a social, cultural and identity phenomenon. We establish an articulation between deaf literature and the social and school education of the deaf, reflecting on the processes that enabled them to build a reading repertoire and on the interfaces of this context with the policies that reaffirmed the bilingualism of the deaf and the right to use Libras. The experiences of socialization and schooling with literature and the Portuguese language tell about the trajectories of the deaf community and often prove to be bumpy, especially by the presence of clinicaltherapeutic processes of insertion in the hearing community. However, the reported experiences also indicated a favorable engagement in social practices of literary literacy, either as readers who evaluate in a contextualized way certain productions or as authors who experience literary performances that are enhanced by social networks that circulate representative productions of the deaf community, which includes the systematic use of Libras.

Keywords: deaf literature; literature in Libras; deaf reader education; bilingual education; literary literacy.

\section{INTRODUÇÃO}

Neste artigo discutimos a formação de leitores literários em um contexto de minoria social: a comunidade surda ${ }^{1}$ usuária da Língua Brasileira de Sinais (Libras). Considerando o bilinguismo dos surdos², Libras-Português,

* Doutoranda na Faculdade de Educação da Universidade Federal de Minas Gerais (UFMG), Belo Horizonte, MG, Brasil. paulasantos@ educ.dout.ufmg.br

Orcid: https://orcid.org/0000-0002-4699-4309.

** Professor da Faculdade de Educação da Universidade Federal de Minas Gerais (UFMG), Belo Horizonte, MG, Brasil. gilcineicarvalho@ ufmg.br

Orcid: https://orcid.org/0000-0002-3137-5302.

***Professora da Faculdade de Educação da Universidade Federal de Minas Gerais (UFMG), Belo Horizonte, MG, Brasil. tcrocha@ufmg.br Orcid: https://orcid.org/0000-0002-7953-9484.

1. Optamos por utilizar neste texto a expressão 'comunidade surda', de forma singularizada. Contudo, ressaltamos que, pela pluralidade de seus aspectos culturais, regionais e identitários, entendemos que não há uma comunidade única e específica, mas muitas configurações por meio das quais as pessoas surdas se organizam e interagem. Assim, a comunidade surda é plural e multifacetada.

2. Adotamos o termo 'surdo', em detrimento do termo 'deficiente auditivo', seguindo a perspectiva considerada pela própria comunidade surda brasileira. Os surdos, principalmente usuários da Libras, entendem a surdez não focalizando uma perspectiva do nível de "perda" auditiva, mas, sim, valorizando o seu bilinguismo e a diferença nos processos de interação (visual) com o mundo. A compreensão da surdez 
focalizamos as práticas sociais de leitura que envolvem o letramento literário, caracterizando as interações em que a Libras tem centralidade.

As produções literárias desse campo têm sido denominadas principalmente de duas formas: literatura surda e literatura em Libras. De acordo com Sutton-Spence (2021), a literatura surda é a forma como vêm sendo nomeadas as produções que abordam as experiências e a vida de pessoas surdas, geralmente produzidas pelos próprios surdos; e a literatura em Libras são as produções feitas nessa língua e que não necessariamente estabelecem uma relação com as vivências sociais dos surdos.

Karnopp (2010, p. 171) explica que as produções pertencentes ao que se conhece como literatura surda são constituídas "pelas histórias produzidas em língua de sinais pelas pessoas surdas, pelas histórias de vida que são frequentemente relatadas, pelos contos, lendas, fábulas, piadas, poemas sinalizados, anedotas, jogos de linguagem e muito mais". Nessa concepção, há um entendimento de que o adjetivo surda caracteriza produções que enfocam a questão social da surdez, indicando, inclusive, a existência de produções em Libras, que não necessariamente poderiam ser consideradas como parte dessa literatura.

Tomamos como referencial teórico estudos do campo dos letramentos literários (COSSON, 2006; PAULINO, 2010), da formação de leitores literários (ANDRUETTO, 2012; FINNEGAN, 2015), da literatura surda e da literatura em Libras (PIMENTA, 1999; RAMOS, 2002; CAMPELLO; CASTRO, 2003; OLIVEIRA; OLIVEIRA; CARVALHO, 2008; BASSO; CAPELLINI, 2012; SUTTON-SPENCE, 2021, dentre outros) e da educação bilíngue para surdos (CAVALCANTI, 1999; KARNOPP, 2010; BRITO, 2013; GURGEL; KARNOPP, 2015; COSTA, 2020, dentre outros) para qualificar o debate político e pedagógico sobre a formação de leitores surdos e suas trajetórias de envolvimento em práticas sociais de letramento literário.

Para a compreensão de algumas dessas trajetórias, trazemos, como parte das nossas discussões, entrevistas realizadas com dois professores surdos, de diferentes gerações, que nos relataram seus processos de formação leitora e como as produções da literatura surda e da literatura em Libras repercutem em suas atuações profissionais. As entrevistas nos possibilitaram situar valores e expectativas sobre as práticas de letramento literário nas esferas familiar, escolar e profissional, apontando para uma dimensão sócio-histórica que marca a produção e negociação de sentidos nas ações de leitura, permitindo-nos tensionar o próprio conceito de literatura e de letramento literário.

\section{CONCEPÇÕES DE LITERATURA E LETRAMENTO LITERÁRIO}

A tarefa de caracterizar um fenômeno social e de produzir categorias de análise é sempre reveladora de uma ação política que, ao enquadrar um determinado objeto, acrescenta uma agenda de defesa de um ponto de vista e de instauração de um posicionamento que certamente produzirá certas atitudes de adesão ou de refutação.

No questionamento sobre os efeitos políticos de um processo de adjetivação da literatura, particularmente em relação às esferas infantil ou juvenil, Andruetto (2012), no seu livro de ensaios intitulado Por uma literatura sem adjetivos, aponta os lugares sociais e os objetivos derivados de uma referência que institui diferentes expectativas:

Assim, à literatura para adultos ficam reservados os temas e as formas que são considerados do seu pertencimento, e a literatura infantil/ juvenil é, com demasiada frequência, relacionada ao funcional e ao utilitário, convertendo o infantil/juvenil e o funcional em dois aspectos de um mesmo fenômeno (ANDRUETTO, 2012, p. 61).

A crítica ao caráter funcional e utilitário da literatura é derivada de uma nomeação que, tomando como parâmetro um mundo adultocêntrico, tende a fazer julgamentos baseados em critérios de simplicidade e de facilidade que são anexados ao universo infantil, em especial quando o texto literário e a literatura são tomados como pretexto para um processo de ensino, quer em contextos familiares quer em contextos escolares, marcados por um processo de 'pedagogização' das práticas de letramento (Cf. STREET, 2014). Como práticas sociais legítimas e, principalmente, legitimadas por um letramento dominante, não só gêneros literários são alçados a uma condição de referência cultural

nessa perspectiva, chamada de sócio-antropológica, vem sendo entendida como potencial desencadeadora de atividades culturais e de identidades singulares, contribuindo para que a construção da educação de surdos possa ser sustentada por reflexões de campos do saber que trazem perspectivas mais sociais, como os estudos dos letramentos e a própria sociolinguística. Segundo Rodrigues (2018, p. 176) "a defesa, feita pelos próprios surdos, pelo uso da língua de sinais na educação, cada vez mais ganhou consistência social e reconhecimento político, tornando-se a grande bandeira do movimento surdo atual". 
imprescindível e recomendável, mas, principalmente, certas mediações são favorecidas, legitimando uma leitura considerada preferencial.

O reconhecimento de condicionantes sócio-históricos para as práticas de letramento, literárias ou não, instituem a constatação de ausência de neutralidade nessas práticas e encaminham uma direção de entendimento que não pode minimizar uma dimensão social dos valores a que estão inegavelmente atrelados. Por isso, se a crítica ao utilitarismo de certos adjetivos encontra amparo em uma avaliação reducionista da literatura, por outro lado sinaliza um posicionamento de interesse, especialmente quando se considera a promoção de um lugar de destaque na literatura como instituição, repercutindo em várias esferas, como a editorial, a escolar, a acadêmica, só para citar algumas mais evidentes. Por isso, acompanhamos Paulino (2010) quando afirma que "o letramento literário, como outros tipos de letramento, continua sendo uma apropriação pessoal e consciente de práticas sociais de leitura/escrita, que não se reduzem à escola, embora muitas vezes passem por ela." (p. 407). Para Cosson (2006), a escola é um dos principais mediadores, na apropriação do letramento literário, mas para que essa mediação seja efetiva, é preciso que haja um processo educativo específico, em detrimento de uma mera e simplista leitura de textos considerados literários e valorizados por esta instituição.

Apropriação pessoal de uma prática social, eis uma caracterização adequada das tensões que estão alimentando o debate sobre as adjetivações escolhidas: se por um lado há a identificação de traços de um sujeito (criança/adulto; surdo/ouvinte), por outro há a contextualização de um lugar social da literatura em que mecanismos de produção, circulação, promoção e mediação determinam o que se lê, por que se lê, onde se lê ... ultrapassando a ideia de um gesto individual. Por isso, também, "a literatura é, portanto, uma construção que vai até mesmo além do livro como objeto de cultura" (ANDRUETTO, 2012, p. 62) e dimensiona práticas sociais que ultrapassam, em muito, a cultura do impresso ou a concepção de leitura como ação isolada e solitária.

Como representativa de um movimento de questionamento da 'grande divisão' entre oralidade e escrita, Ruth Finnegan (2015) debate sobre o lugar da literatura, pensada não só na dimensão de seu suporte, mas principalmente em termos de práticas sociais em que a ideia de performance adquire uma centralidade, em especial para certos gêneros em que entram em jogo uma enunciação em que a linguagem precisa ser dimensionada de forma mais ampla. O proposto por Finnegan colabora para essa ampliação do estudo da literatura, evitando-se o reducionismo da linearização da palavra, via processos exclusivos de uma leitura de apenas decodificação.

Nesse cenário de ampliação dos conceitos de linguagem e de literatura é que se encontram os elementos conceituais para justificar o uso de adjetivo na expressão literatura surda, considerando uma especificidade identitária que dimensiona o processo de leitura em uma complexidade constitutiva em que já estariam eliminadas as visões reducionistas e utilitaristas. Essa defesa da adjetivação, no entanto, não pode minimizar as dinâmicas sociais, sob pena de favorecer um essencialismo que provoca um enquadramento determinístico do fenômeno, como se a caracterização da literatura surda fosse, por exemplo, um rótulo homogêneo e singular atribuído por traços transparentes. Essa tendência, na verdade, é favorecida pelo processo de escolarização que, além de priorizar certas concepções idealizadas de leitura, tende a hierarquizar textos e repertórios literários. Por isso, conforme Paulino (2010), "o ensino de literatura, como parte do processo de letramento literário, se mistura ao contato com outros tipos de textos, numa contaminação incessante, que tem de ser considerada não apenas na escola, mas em todas as instâncias sociais." (p. 407).

Corroborando com este entendimento, Cosson (2006) ainda argumenta que, abordada por meio de quatro fases: motivaçãa, introdução, leitura e interpretação, a literatura pode atuar na compreensão da forma como os textos são compostos, mas, para além disso, é possível que sentidos sejam produzidos, na direção de um autoconhecimento. Ao possibilitar uma conscientização acerca de si e de seu papel, enquanto indivíduo situado em um contexto sócio-histórico, a mediação literária favorece possíveis transformações na ordem social, o que pode justificar que a comunidade surda lute pela legitimidade de uma literatura para, dos e sobre os surdos. Além da construção identitária, o repertório leitor também constitui as práticas de mediação literária.

Talvez, essa "contaminação incessante" (PAULINO, 2010, p. 407) seja um elemento que funciona como um forte argumento para relativizar a força das adjetivações, sem desconsiderar o alcance político das formas de demarcação de certos territórios de luta, como aqueles vivenciados pela comunidade surda. Essa demarcação, entretanto, não pode resultar em secundarização do substantivo literatura, como se já houvesse um consenso absoluto sobre esse conceito. O estatuto literário de um texto e também os efeitos de sentido de uma experiência literária estão em um terreno de contestação, quer do ponto de vista histórico, quer do ponto de vista cultural. O princípio 
orientador de nossa análise admite essa disputa exatamente por considerar uma pluralidade de usos da linguagem em diferentes tempos e espaços, o que nos alerta para o perigo de classificações que menosprezam a dinâmica social, especialmente em contextos de bilinguismo focados neste artigo.

\section{LITERATURA SURDA E LITERATURA EM LIBRAS: DA CONSTITUIÇÃO DAS PRODUÇÕES AOS SEUS USOS ESCOLARES}

As discussões em torno da literatura surda envolvem questões como o registro de tradições contadas e recontadas em Libras, a representatividade de pessoas surdas como personagens de histórias, as performances com a exploração de recursos visuais, as políticas linguísticas e as formas de resistência por meio de criações culturais em línguas que carregam o estigma de serem consideradas de menor prestígio, como as línguas sinalizadas (MAHER, 1997; CAVALCANTI, 1999; MEGALE, 2018).

A ampliação da visibilidade e o crescimento das produções literárias em Libras, no Brasil, certamente estão ligadas a dois grandes movimentos: (a) o desenvolvimento de políticas linguísticas e de políticas de acessibilidade e (b) o avanço no uso de tecnologias digitais para registro, comunicação e divulgação (QUADROS, 1997; KARNOPP, 2010; SUTTON-SPENCE, 2021).

Em relação às políticas linguísticas e políticas de acessibilidade, as mais expressivas nesse campo estão ligadas ao reconhecimento da Libras como língua em 2002 e a regulamentação de questões ligadas ao seu uso nos espaços escolares e não escolares em 2005. Acrescentam-se, nesse cenário, as políticas que reafirmaram o bilinguismo dos surdos e legitimaram a acessibilidade enquanto um direito (BRASIL, 2002, 2005, 2014, 2015). Muitas dessas políticas decorrem do engajamento dos próprios surdos e de suas entidades representativas ${ }^{3}$ em movimentos sociais e em espaços político-institucionais (BRITO, 2013) de reivindicação e de luta por direitos.

Já em relação às tecnologias de registro, comunicação e divulgação, podemos fazer referência desde produções como as poesias gravadas em VHS no final dos anos 1990 e início dos anos 2000 (cf. PIMENTA, 1999)4, até o uso mais recente de e-books, aplicativos de celular e, principalmente, vídeos no YouTube. Com a ampliação e a popularização desses recursos, a literatura surda tem alcançado mais espaços e leitores/espectadores, passando inclusive a ser disciplina lecionada no Ensino Superior, nos cursos de Letras-Libras (SUTTON-SPENCE, 2021).

Considerando essas diferentes formas de registro e suporte, em nossa busca por produções da literatura surda e da literatura em Libras, nos foi possível estabelecer pelo menos cinco categorias, as quais listamos a seguir, procurando nos aproximar da ordem cronológica na qual diferentes produções se situam:

i. Tradução de obras clássicas, feita por tradutores-intérpretes de Libras, surdos ou ouvintes, com registro em vídeo: nessas obras, geralmente os intérpretes aparecem em primeiro plano ou em uma janela na lateral do vídeo e, ao fundo, são mostradas imagens da obra que complementam a narrativa visual. Alguns exemplos de traduções difundidas na comunidade surda são: As Aventuras de Pinóquio, de Carlo Collodi (CAMPELLO, CASTRO, 2003), e Iracema, de José de Alencar (RAMOS, 2002). Essas obras, interpretadas em maioria por autores surdos, foram publicadas em VHS e em DVDs no início dos anos 2000, como parte da coleção 'Clássicos da Literatura em Libras/Português' e, posteriormente, com o apoio do Governo Federal, foram distribuídas para diversas escolas e universidades do país.

ii. Reescrita de obras clássicas, com adaptações na narrativa que passa a incluir personagens surdos em formato impresso: em muitas dessas obras, como, por exemplo, o livro A Cinderela Surda, publicado pela primeira vez em 2003 (SILVEIRA, ROSA, KARNOPP, 2011), são explorados desafios e barreiras sociais enfrentadas pela comunidade surda. Nessa obra, há o uso da escrita de sinais (SignWritting), além do português e da presença de

3. A comunidade surda brasileira se organiza por meio de diversas associações e entidades existentes nas diferentes regiões do país, sendo algumas delas quase centenárias. Essas entidades se constituíram como um local de interação em Libras, principalmente quando a língua não era reconhecida e não circulava em espaços como as escolas, por exemplo. Até então, a Libras era utilizada por algumas famílias, em igrejas e outros contextos sociais não institucionalizados. As associações proporcionaram aos surdos a possibilidade de se reunirem para discutir determinadas pautas políticas da comunidade e realizarem atividades culturais, como a contação de histórias em Libras, apresentações teatrais, entre outras. Atualmente a entidade representativa que mais tem se mobilizado por direitos aos surdos junto aos diferentes níveis de governo é a FENEIS - Federação Nacional de Educação e Integração dos Surdos.

4. De acordo com Sutton-Spence (2021), essa produção feita pelo prof. surdo Nelson Pimenta, pode ser considerada como o primeiro ou um dos primeiros registros no Brasil de uma obra de literatura surda. Nessa fita VHS, além de traduzir duas histórias, o autor também conta 3 poemas originais, produzidos em Libras. 
ilustrações. Nas produções que envolvem reescrita, geralmente há uma ampla exploração do aspecto visual, por meio do uso de imagens que mostram personagens surdos, com expressões faciais destacadas e usando a Libras em suas interações.

iii. Reconto de obras clássicas, com performance em Libras e registro em vídeo: nessas obras, os atores, surdos ou ouvintes, usuários da Libras, assumem o papel dos personagens em uma encenação, como, por exemplo, em Chapeuzinho Vermelho em Libras (INES, 2012). Nessa produção, a caracterização com figurino, o cenário e o uso de fantoches contribuem para a atuação que é intercalada com a contação da história.

iv. Escrita de obras originais com registro impresso, em livros, e personagens surdos ou narrativas sobre vivências da comunidade surda: um exemplo desse tipo de produção é a obra Um mistério a resolver: o mundo das bocas mexedeiras, na qual a personagem principal, que é surda, tenta entender por que as pessoas ao seu redor 'mexem' a boca e conseguem o que querem e ela, ao mexer a boca da mesma forma, não é compreendida por ninguém (OLIVEIRA; OLIVEIRA; CARVALHO, 2008). A obra explora o aspecto visual, com ilustrações em páginas inteiras e destaque às mãos dos personagens. Além disso, o livro é acompanhado de um DVD com a tradução da história para a Libras e orientação pedagógica, na qual são exploradas sugestões de trabalho com alunos surdos.

v. Criação de obras originais em Libras, com registro em vídeo, e personagens surdos ou narrativas que envolvem a Libras: nesse formato, têm sido criadas produções de diversos gêneros, como piadas, poesias, contos, fábulas, entre outros. Plataformas como o YouTube, TikTok, Instagram e Vimeo têm sido amplamente utilizadas para a publicação e a divulgação dessas produções. Diversos exemplos de produções dessa categoria podem ser encontrados nos Anais do Festival Despertacular, realizado em formato digital em 2020, durante a pandemia de Covid-19, com o suporte de ferramentas de diversas redes sociais. O evento foi realizado por surdos, de diversos Estados do Brasil e de outros países, e contou com performances ao vivo e exibições gravadas de variados gêneros literários em Libras e também com a realização de saraus e slams ${ }^{5}$ (REZENDE, 2020).

Nessa breve listagem de uma cronologia das obras, é possível identificar uma política de ampliação de vivências que incluam a presença da surdez, quer seja pela via temática que mobiliza o necessário debate, quer seja pela via tecnológica que disponibiliza recursos para potencializar produções de sentidos instauradas pelas várias linguagens. A ampliação, portanto, está sinalizada pela seleção de conteúdos e pela variedade de suportes.

Karnopp (2010) destaca, ao analisar essas produções - sejam elas as obras impressas da literatura surda, as traduções de histórias orais para a Libras, as adaptações dessas histórias para o contexto da comunidade surda ou as criações feitas diretamente em Libras -, a forte presença da questão da representatividade. Segundo a autora, em geral, essas são produções feitas por pessoas surdas e consideram aspectos políticos e identitários, em busca da visibilidade de aspectos sociais, culturais e linguísticos da comunidade. Essas questões, identificadas pela autora, podem ser notadas, por exemplo, na obra Cinderela Surda, na qual é realizada uma reescrita e adaptação do clássico de 1812, de autoria de Wilhelm Grimm e Daisy Fisher. Os autores da versão reescrita da obra informam:

A maioria das pessoas conhece a clássica história da Cinderela. Nosso objetivo, aqui, é recontar essa história a partir de uma outra cultura, uma cultura surda. Assim, este livro foi construído a partir de uma experiência visual, com imagens, com o texto reescrito dentro da cultura e identidade surda e da escrita da língua de sinais, conhecida também como SignWriting.

Utilizamos a escrita dos sinais para que textos dos clássicos da literatura sejam também lidos pelos surdos. Cabe registrar que, no texto, as palavras em letras maiúsculas representam os sinais.

Cinderela é uma jovem surda que convive com a madrasta e as irmãs, que sabem pouco a língua de sinais. O encontro com o príncipe é surpreendente, pois ele é surdo e comunica-se com Cinderela em sinais (SILVEIRA, ROSA, KARNOPP, 2011, p. 05).

A síntese de Cinderela Surda, realizada pelos autores, nos fornece pistas sobre as especificidades desta literatura, como a valorização do uso da língua de sinais, a presença de protagonistas surdos e a exploração de temáticas comuns na comunidade surda. Karnopp (2010) enfatiza que essas abordagens, muitas vezes, recontam experiências de pessoas surdas, contribuindo para possibilitar o contato com visões diferentes sobre suas vivências e para se pensar possíveis desfechos de relações conflituosas ou desafiadoras enfrentadas por eles.

5. De acordo com Neves (2017) slams correspondem a batalhas ou campeonatos de poemas, que são realizados de maneira performática, proporcionando a presença de "novas vozes" e "novas realidades" ao contexto de produção cultural. As produções muitas vezes são marcadas por temas sociais cotidianos para os slammers, como, por exemplo, o racismo, o preconceito, a desigualdade, o sexismo, dentre outros, ressaltando a necessidade de sua discussão crítica. Na comunidade surda, os slams ocorrem de forma performática em Libras. É possível encontrar uma reportagem que esclarece o tema no seguinte endereço: https://www.escrevendoofuturo.org.br/blog/literatura-emmovimento/poetas-do-corpo-slam-mostra-a-voz-dos-surdos/. Acesso em: 25 jun. 2021. 
Em produções mais recentes da literatura surda, outros campos vêm sendo também explorados, como o universo das artes, com poemas baseados em obras que compõem acervos de museus e outros gêneros nos quais o humor, "rimas de sinais" e outros elementos aparecem com destaque. Nessas produções, há o que Mourão (2016) e Sutton-Spence et al (2020) chamaram de "oportunidade de brincar com Libras". Os leitores ou visualeitores são convidados para a imaginação, o deleite e a imersão em um universo visual e de uma sinalização mais livre, com maior exploração performática. Nessa direção, o conceito de literatura passa a ser alargado, seguindo a complexidade de práticas e a multiplicidade de formas, apontadas por Finnegan (2015).

A presença da temática surda nas produções literárias, aliada a uma ampliação dos modos de produção e de circulação dessa literatura, certamente produz a indagação sobre as suas potenciais repercussões na esfera escolar. Nessa direção, essa produção literária não pode ser analisada descolada de um contexto histórico que debate as concepções de ensino e de aprendizagem preconizadas por discussões que envolvem tanto o processo de escolarização quanto, principalmente, a teorização sobre a surdez.

De acordo com Rodrigues (2018), há uma reconfiguração na educação oferecida às pessoas surdas, tendo em vista a mudança na forma como essa educação e as próprias pessoas surdas, têm sido entendidas nas últimas duas décadas. Uma visão social e histórica passa a ser considerada, em detrimento de uma visão clínico-terapêutica, que entende a surdez como uma deficiência. Nesse contraponto, há

(...) a visão da surdez como fenômeno cultural e linguístico; o reconhecimento das línguas de sinais; a inauguração de estudos linguísticos sobre elas; o fortalecimento do movimento surdo comunitário e acadêmico e, também, a instauração do paradigma inclusivo como proposta de orientação das ações e das políticas voltadas à educação. Essas mudanças históricas, intensificadas a partir da década de 1990, proporcionaram a implantação de propostas educacionais diretamente voltadas aos surdos e fomentaram diversas ações políticas e pedagógicas bilíngues no processo de escolarização (RODRIGUES, 2018, p. 76).

Nesse trecho, são indicados elementos que situam certos condicionantes sócio-históricos que favoreceram, em maior ou menor grau, a implantação de propostas educacionais mais contemporâneas. A inovação, no entanto, não se efetiva com rupturas automáticas. Obras que partem de contextos oralizados, apenas traduzidas para a Libras, também podem agregar um potencial para a abordagem da língua e das vivências da comunidade surda, como demonstram autores como Basso e Capellini (2012), por exemplo.

\section{LEITURA E LITERATURA: TRAJETÓRIAS DE DOIS PROFESSORES SURDOS}

A análise de trajetórias acadêmicas de docentes surdos constitui uma agenda ampla de pesquisa quando se pretende investigar as suas práticas sociais de letramento em várias esferas de atividades, o que dimensiona a possibilidade de focar os letramentos nos mais diversos adjetivos: acadêmico, literário, profissional, só para enumerar alguns.

Tendo em vista estabelecer uma articulação entre a literatura surda e a formação social e escolar de pessoas surdas, nos valemos, neste artigo, de duas entrevistas com professores surdos, considerando o entendimento produzido acerca da forma como suas experiências na construção de um repertório leitor refletem em seu trabalho atualmente, em meio ao uso da literatura surda. As entrevistas foram realizadas em maio de 2021, por meio da plataforma Skype, em função do contexto de restrição sanitária provocada pela pandemia Covid 19. As interlocuções foram previamente agendadas e seguiram um formato semiestruturado. A escolha dos entrevistados foi favorecida pela rede de contatos de uma das autoras com a comunidade surda que, inclusive, realizou a interpretação para a Libras durante as entrevistas. O uso da Libras foi majoritário, com a interpretação sendo intercalada nos momentos da interação, quer para a troca de turnos, quer para o esclarecimento de algum tópico. As transcrições que aparecem neste artigo tomam a tradução da intérprete como referência. Essa opção, inclusive, foi negociada com os entrevistados sob o entendimento de que facilitaria o trabalho de apresentação de uma versão em língua portuguesa. Os participantes foram identificados por pseudônimos escolhidos por eles, tendo em vista as questões éticas que permeiam os processos de pesquisa ${ }^{6}$.

6. Este estudo foi submetido ao Comitê de Ética em Pesquisa (COEP), sendo aprovado e registrado pelo identificador: CAAE 00208118.9.0000.5149. 


\subsection{Trajetória de Luana}

A nossa primeira participante entrevistada, identificada com o pseudônimo Luana, tem aproximadamente 50 anos, é licenciada em Pedagogia e atua em uma escola Estadual para surdos em Minas Gerais. Conforme explicitou durante a entrevista, Luana acredita ter sido uma das primeiras pedagogas surdas no Estado. Ela destacou a importância da figura da mãe em sua inserção no "mundo ouvinte", na busca pelos primeiros estímulos para que passasse a ouvir e/ou se oralizasse. Em sua infância, a curiosidade pela televisão era algo que a instigava, com conteúdos geralmente explicados pela mãe, de forma oral e gesticulada, para que ela pudesse, de alguma forma, ser inserida nessa prática social, ao longo do acompanhamento das programações.

Mais tarde, nesse processo de mediação, a mãe lhe destacou a importância do aprendizado de metáforas para a construção de um entendimento do mundo ao seu redor. Esses conhecimentos eram apresentados a Luana em forma de gestos negociados, de forma situada, entre ela e a mãe, que resolveu cursar a graduação em Pedagogia para melhor auxiliá-la. Luana apresenta uma avaliação das práticas familiares, principalmente quando envolviam uma mobilização para as tarefas escolares:

Era muito diferente de hoje, a gente não tinha nada de recursos e informações $(+)$. E aí, o que que minha mãe fazia? Ela fazia um esforço de 'para casa' $(+)$, quando eu ia fazer 'para casa', ela sempre estava junto comigo, me acompanhava sempre $(+)$, a gente estava sempre junto. E também ela ficava pensando: como é que eu vou ensinar minha filha? E ela falava comigo assim: "filha, vocêprecisa entender metáforas, você precisa abstrair, ter abstrações, criar abstrações" $(+)$ e isso era muito difícil pra mim, era muito pesado e a minha mãe pensava em como me proporcionar isso $(+)$, porque eu tinha, por exemplo, uma experiência concreta, eu pensava muito na experiência concreta, na verdade $(+)$, e aí eu precisava ter um pensamento no qual eu compreendesse melhor as abstrações, as metáforas. E aí, ela começou a pensar em contextos, talvez, de teatro, alguma coisa que pudesse me incentivar, por exemplo, que eu visse o que havia por trás (...) (ENTREVISTA, LUANA, 20/05/2021) ${ }^{7}$.

O aprendizado sistematizado de metáforas como um incentivo de sua mãe, de acordo com Luana, contribuiu para a sua compreensão de mundo e, também, para o desenvolvimento de um imaginário que posteriormente lhe permitiu produzir abstrações das produções literárias. Costa (2020) ressalta, em seu estudo, a importância da aquisição vocabular por meio do aprendizado de metáforas. A autora salienta que esses estudos não têm sido explorados durante o ensino de língua portuguesa como segunda língua para estudantes surdos. A autora avalia que esse entendimento do sentido metafórico de determinadas expressões, em contraposição à interpretação literal, é bastante relevante para as interações sociais.

Silva (2014) também reforça essa necessidade, indicando que, mais que acesso a materiais escritos, as políticas educacionais devem oportunizar a aprendizagem de português, tendo em vista seu status como segunda língua para estudantes surdos, por meio de relações contextuais. Estudos indicam que essa aprendizagem é permeada por longos processos de escolarização, decorrentes de atividades que buscam a normalização do surdo à maioria ouvinte, o que desconsidera aspectos identitários e culturais e tenciona uma visão do surdo como deficiente e, como tal, carente de cuidados médicos e terapêuticos (SILVA, 2014; QUADROS, 1997).

Para Luana, o tratamento que lhe foi oferecido buscava fazê-la ouvir e falar, em muitos casos, com profissionais que 'tapavam' as próprias bocas, forçando-a a ouvir, evitando, assim, a pura leitura labial. Nesse período, Luana interagia e se identificava apenas com pessoas ouvintes. O relato de Luana marca uma trajetória conhecida da comunidade surda: uma primeira e prolongada socialização familiar, com um direcionamento à oralização, com predominância de abordagens clínico-terapêuticas. De acordo com Quadros (1997), esse conhecido percurso fundamenta-se na "recuperação" dos surdos, como se devessem obrigatoriamente ser ouvintes, enfatizando as línguas de predominância oral-auditiva nas abordagens terapêuticas. Outra abordagem utilizada pela mãe de Luana, a leitura labial, é também abordada por Quadros (1997), como uma prática pouco eficaz, já que a criança surda apresenta uma baixa captação da mensagem, por meio da leitura labial, funcionando, na maioria dos casos, apenas entre o núcleo familiar, com as pessoas que convivem com essas crianças (QUADROS, 1997). Não se trata, aqui, de promover uma crítica simplista sobre a forma como a mãe de Luana conduzia sua socialização, mas, sim, estabelecer uma relação entre a trajetória da professora e sua atuação, entendendo-a importante para que, hoje, Luana desenvolva, agora na condição de professora, estratégias mais voltadas à aquisição linguística das pessoas surdas, tendo em vista a priorização do canal visual, conforme abordaremos adiante.

7. A convenção utilizada nas transcrições foi feita com base em Marcuschi (1999), na qual o símbolo (+) indica pausas ou silêncios. As pequenas pausas, de até 0.5 segundo são representadas pelo sinal ' + '. As pausas com mais de 1.5 segundo foram cronometradas e apresentadas entre parênteses e com o indicativo do tempo de duração em segundos como, por exemplo, $(1,5)$. 
No que diz respeito aos materiais com os quais teve acesso durante sua escolarização, Luana também relatou a presença de livros infantis, destacando as palavras-cruzadas e outros materiais oferecidos pela mãe, sem uma orientação mais sistematizada da escola ou de outros profissionais. Ela ressaltou que, no contato com os livros, as ilustrações a auxiliaram na aquisição de vocabulário. Durante sua escolarização, Luana não foi atendida por intérpretes de Libras ou contemplada com abordagens inclusivas no ensino. Segundo ela, na escola, durante os processos de aprendizagem dos conteúdos, por ter que se manter concentrada nos lábios de seus professores e na leitura do quadro, sistematicamente pedia emprestado os cadernos dos colegas para, após as aulas, copiar as anotações e revisar o que pudesse ter perdido.

Ao se formar em Pedagogia, Luana informou que iniciou, em 1999, a sua trajetória profissional em uma escola especial, lecionando para surdos no Ensino Fundamental I. Uma de suas maiores preocupações nessa atuação, conforme destacou, permanece até a atualidade: a predominância de materiais didático-pedagógicos e literários voltados apenas para alunos ouvintes. Diante disso, a professora enfatizou os usos que fazia de produções literárias clássicas, no formato original impresso, preferencialmente as que possuíam imagens, para que pudesse utilizar nos processos de mediação do aprendizado da língua portuguesa escrita e da Libras para as crianças surdas. $\mathrm{O}$ trecho da entrevista, a seguir, ilustra esses processos de mediação:

Às vezes o que estava nos materiais era muito pesado para aqueles alunos compreenderem $(+)$ e pra mim, eu pensava em adaptar e
focalizar em algum conteúdo, para suprir aquilo que estava ali no livro $(+)$. Por exemplo, tinha um texto no livro e eu sempre olhava
para aquilo, tentando por exemplo focar, pela imagem, pelo desenho, aproveitava aquela imagem, explorava, mostrava para os meninos
os sinais, por exemplo, podia ser um animal: "qual o sinal deste animal? Qual é o nome dele?" (+). Eu ia pegando aquilo pelo contexto, para
depois sim, fazer com que eles compreendessem o contexto da frase (+). Eu ia pegando partes pequenas, tentando contextualizar a
partir de algo bem simples para fazer com que eles pegassem, por exemplo, de alguma palavra, por exemplo: "quem éo sujeito, qual éo verbo,
o que ele fez, o que vem de predicado?" (+). E aí a gente ia trabalhando, por exemplo, eu mostrava pra eles o gato, imaginando aqui, só um
exemplo, "e aí o gato comeu, o que? (+) comeu um pão". Então, para que a criança pudesse escrever aquilo no quadro, identificar, fazer frases
livremente etc., e eu olhando a partir daquilo, e aí eu pegava o desenho pra que esses meninos pudessem entender a comunicação,
entender uma frase, e aí 'o gato comeu o pão'. E aí, quando eu ia mostrar pros meninos o gato, fazer a conexão dessa palavra, eles não
conheciam, eles não sabiam o que era gato, vendo aquilo ali isolado (ENTREVISTA, LUANA, 20/05/2021).

Luana enfatizou ainda que, em um dado momento no final dos anos 1990 e início dos anos 2000, era a única professora surda na escola onde trabalha, e se constituía assim como modelo para os alunos surdos. Segundo a entrevistada, seus alunos eram oriundos de contextos diversos e poucos deles entraram na escola já conhecendo a Libras. Eram comuns nesse contexto dificuldades de interação dos alunos com as suas famílias, realidade também experienciada por Luana. Ao identificar essa situação, a escola também passou a oferecer aulas de Libras para os pais das crianças. Outro fato destacado na entrevista é a resistência das famílias ao ensino de Libras como primeira língua dos filhos, o que, em alguns casos, acarreta em dificuldades para o auxílio às atividades escolares. Segundo Quadros (1997, p. 108), os pais, geralmente, não têm modelos ou experiências próximas sobre como serem pais de crianças surdas. "Além disso, eles não conhecem a língua de sinais [...] é fundamental que sejam previstos programas que incluam os pais das crianças e a interação desses com adultos surdos".

Ainda no que diz respeito às produções literárias, Luana enfatizou a centralidade das obras em sua atuação profissional. De acordo com a entrevistada:

Eu sempre utilizei livros literários, principalmente para explorar a questão visual, os desenhos (+) e eu partia dos desenhos, das frases, para poder ensinar pra essas crianças, para elas poderem sinalizar $(+)$. Por exemplo, quando eu pego o livro 'Três Porquinhos', eu pegava, falando com os alunos, qual é o... "qual você vai escolber? Você vai ser esse porquinbo? Você vai ser esse e você vai ser esse" (+). E aí a gente fez um teatrinho em sala de aula e os meninos encenavam esses porquinhos $(+)$. E aí, a partir do desenho, desse referencial do desenho, eu ia mostrando para os meninos e eles identificavam no livro: "você é qual? Eu sou esse, eu sou esse e eu sou aquele" (+). Então, a gente fazia um teatrinho dentro da sala de aula e era dessa forma que eu $(+)$, sempre em roda, trabalhando em grupo com eles, conseguia explorar essas produções literárias $(+)$. E eu acho que elas são importantes por causa do canal visual (1.5). Eu sempre, pensando nessa questão do desenho, eu sempre trabalhei com contação de história para os meninos, eu mostrava pra eles os personagens: "o que ele fez? Quem é essa pessoa? Qual é o animal? O que que ele tá fazendo agora?" $(+)$. E aí eu perguntava para os meninos e eles iam me respondendo $(+)$, para eu ver se eles estavam compreendendo a leitura. Mas, sempre partia dessa percepção visual, eles conseguiam, às vezes, entender pelo contexto, ou pela imagem, e refletir. E aí eu ia acompanhando com eles passo a passo pra ver se eles estavam entendendo corretamente (ENTREVISTA, LUANA, 20/05/2021).

Em relação ao uso da literatura em sala de aula, Luana destacou que sempre utilizou livros literários, com foco na exploração das imagens. As histórias foram utilizadas por ela também para atividades de encenação, com trabalhos em roda e estabelecendo relações com os personagens e o contexto imediato dos alunos. Luana informou que atualmente, com a publicação de livros de literatura surda e a disseminação de contação de histórias em Libras 
pelo YouTube, as possibilidades para as crianças surdas se ampliaram, já que o acesso à literatura não necessariamente precisa ficar centrado na figura da professora, nem no suporte apenas impresso. Essa expansão do acesso também proporciona às crianças conhecerem outros surdos, o que auxilia na construção de suas identidades. "A transição da identidade ocorre no encontro com o semelhante, em que se organizam novos ambientes discursivos. É o encontro surdo/surdo" (SKLIAR, 1999, p. 11), sendo a comunidade surda a sua referência de 'normalidade' (QUADROS, 1997).

\subsection{Trajetória de Henrique}

O segundo entrevistado, identificado pelo pseudônimo Henrique, tem pouco mais de 30 anos, é graduado em Arquitetura e em Letras-Libras e, atualmente, está cursando o mestrado profissional em Educação Bilíngue pelo Instituto Nacional de Educação de Surdos (INES). Seus interesses de pesquisa se relacionam à produção literária no universo da comunidade surda, participando de projetos de literatura surda, como o Mãos Literárias ${ }^{8}$.

Em seu relato, Henrique demonstrou ter tido um acesso reduzido à literatura na infância, possivelmente pelos desafios do aprendizado da língua portuguesa. Contudo, realizava a leitura de quadrinhos guiado principalmente pelas imagens. A leitura de obras como Harry Potter e Sherlock Holmes, por volta dos 13 anos, despertou seu interesse pela literatura e também pela leitura em língua inglesa. Segundo Henrique, em sua infância e adolescência, ele interagiu em língua portuguesa e apenas ao ingressar no curso superior de Arquitetura, diante do desafio de entender as aulas, solicitou apoio ao núcleo de inclusão da universidade, que encaminhou intérpretes de Libras para atendê-lo. Assim, a Libras era sinalizada, mas ainda com o suporte da oralização, com a movimentação dos lábios, pelos intérpretes para ajudar a compreensão. Após esse primeiro contato com a língua, Henrique passou a estudar a Libras. A imersão despertou a sua identidade enquanto surdo, aproximadamente aos 19 anos de idade. Esse período foi marcado pela inclusão de intérpretes de Libras em sua rotina e sua interação em diversos grupos sociais com pessoas surdas. Até aquele momento, Henrique apenas conhecia a comunidade ouvinte, comunicando-se pela fala oral em português, considerando, inclusive, que sua primeira língua tenha sido a língua portuguesa. No fragmento abaixo, o seu aprendizado da língua portuguesa é enfocado:

Minha primeira língua, de fato, era a língua portuguesa $(+)$, e era um esforço muito grande pra mim, meus pais, em relação à leitura $(+)$, pra mim era bastante desanimador e essas questões conceituais e etc $(+)$, era dificultoso, então era nesse contexto (1.5). quanto ao acesso a livros, por exemplo, era um contato bastante reduzido, a gente tinha muitos textos e eu não compreendia muito as palavras, ficava pensando bastante né, era um esforço muito grande, a prática de leitura pra mim (ENTREVISTA, HENRIQUE, 20/05/2021).

De acordo com Henrique, a sua socialização na leitura em língua portuguesa se pautou em um processo difícil e desanimador, com um acesso reduzido a produções escritas. Conforme aponta Skliar (1999), há um conjunto de práticas dominantes nas quais os surdos são inseridos, tendo em vista uma determinada representação de "normalidade", proporcionando interferências em sua linguagem, seus corpos e suas identidades. Ao mesmo tempo, a pessoa surda é entendida pela sociedade como alguém "menor", geralmente em desvantagem social. Em decorrência de sua surdez, práticas reparatórias são orquestradas, o que implica na desconsideração de políticas de inclusão e formação da pessoa surda, considerando sua cultura e múltiplas identidades. "Nos contextos sociais persiste a ideia errônea de uma representação iluminista do normal, do perfeito, do ouvinte. A sociedade, a família, a escola continuam traçando representações contra qualquer tipo de contestação possível" (SKLIAR, 1999, p. 11). É em um cenário que privilegia a cultura ouvinte, predominante, que os surdos se desenvolvem em trajetórias escolares mais ou menos acidentadas, em decorrência de suas primeiras experiências com a socialização e processos de alfabetização (SKLIAR, 1999).

Tendo em vista a socialização em um ambiente familiar e comunitário com a predominância de ouvintes, bem como a inserção em escolas que não oportunizaram o aprendizado da Libras, a descoberta da comunidade surda, para Henrique, ocorreu de uma forma tardia. Quando passou a ter contato com a Libras ele pôde conhecer, inicialmente, produções como piadas contadas como artefatos culturais e de interação da comunidade surda. De acordo com Skliar (1999), Quadros (1997), e outros autores, em muitos casos, as famílias até impedem o contato entre o filho surdo

8. Projeto promovido pela Faculdade de Letras da Universidade Federal de Minas Gerais, por meio do qual histórias são criadas e contadas em Libras (UFMG-FALE, 2021). Para saber mais sobre o projeto, acessar o link: http://www.letras.ufmg.br/maosliterarias/. Acesso em: 26 jun. 2021. 
e outros surdos, temendo que a língua portuguesa não seja assimilada, em decorrência do aprendizado da Libras; crença essa que tem sido desmistificada pelas experiências de um ensino bilíngue para surdos.

À medida que passou a se inserir na comunidade surda, Henrique começou a participar de cursos de formação para o ensino da Libras na Federação Nacional dos Surdos (FENEIS). Essa formação lhe proporcionou conhecer mais os parâmetros lexicais da Libras ${ }^{9}$, favorecendo um aprofundamento na língua e uma imersão nas possibilidades de formação dos sinais para a produção de poesias, com a exploração dos recursos linguísticos para a produção de efeitos estéticos. De acordo com Karnopp e Hessel (2009, p. 48), "há um uso criativo de configurações de mãos, movimentos, locações e expressões não-manuais". Os poemas em Libras, por exemplo, se abrem "para múltiplas interpretações e construções de sentidos" visuais.

Posteriormente, em 2016, Henrique iniciou o curso de graduação em Letras-Libras, no qual pôde estudar a disciplina Literatura Surda. Essa experiência aconteceu concomitantemente à sua atuação como Arte-Educador no Centro Cultural Banco do Brasil (CCBB), espaço no qual passou a realizar visitas guiadas em Libras, criar poesias sobre as obras para serem apresentadas durante as visitas de surdos e ouvintes e a atuação como ator em apresentações teatrais em Libras - em coautoria com uma intérprete - com textos envolvendo as exposições exibidas naquele espaço. A partir dessas experiências, Henrique iniciou suas pesquisas sobre a literatura surda, que continuam em seu curso de mestrado. O seu trabalho tem sido desenvolvido por meio das produções em poesia, contação de histórias e slams. Ao passar a considerar a literatura para o ensino e aprendizado da Libras, por crianças surdas, Henrique se interessou mais pela área, desenvolvendo-se nesse campo por meio de cursos e parcerias em projetos que já trabalham com a Literatura Surda. Há pesquisas, como a de Gurgel e Karnopp (2015), que demonstram a possibilidade do aumento do repertório vocabular em sinais quando são realizadas atividades de (re)contar histórias, sobretudo quando há uma identificação delas com seu próprio contexto social.

Ao relatar essas experiências, mais especificamente sobre a forma como utiliza a literatura surda, Henrique esclareceu que:

São diversas possibilidades de acesso $(+)$, eu conheci uma professora, a Rachel Sutton, que é professora da UFSC, e tive bastante contato $(+)$ muita interação com ela $(+)$ eu fiz duas disciplinas com ela, a primeira disciplina em relação ao projeto de pesquisa, participei de um projeto de pesquisa de divulgação dela $(+)$. Ao mesmo tempo participei do projeto Mãos Literárias da UFMG, com divulgação de poesias, piadas, contação de histórias em Libras $(+)$, a gente fazia as gravações, né $(+)$, com esse sistema, e nesse universo da arte. Teve um projeto também lá da UFSC, que era de literatura e didática, e abordava questões para o ensino para crianças no Ensino Fundamental $(+)$ e aí nesse projeto, eu sei que assim, a gente tinha poucos livros, poucos materiais para poder utilizar, a gente tinha mais vídeos, mas onde é que a gente ia encontrar esses vídeos, esses vídeos $(+)$ também eram um pouco escassos $(+)$. A gente quase que estava fazendo tradução dos vídeos, das criações, mas aí nós mesmos decidimos que nós íamos criar produções nossas, em língua de sinais, que esses seriam os nossos materiais e a Rachel resolveu nos incentivar a criar esses materiais didáticos $(+)$ profissionalmente, ao invés de traduzir $(+)$ e gente começou a trabalhar nesse projeto. Com esses dois principais contatos, e aprendendo nessas disciplinas que eu comecei a utilizar (1.5) então eu tive contato com Luiz Cláudio Carvalho, ele trabalha no INES (1.5) ele tem um projeto com o ensino de leitura, com questões de leitura literária $(+)$ e ele tem trabalhado utilizando conceitos da literatura surda, são abordagens bastante diferentes desse projeto que eu trabalhei lá na UFSC, ele trabalha com diversos textos e aí ele tem explicado para a gente que ele trabalha com slam, com questões visuais e etc. e tem explicado bastante sobre a diferente abordagem dele $(+)$, as vezes ele parte do texto, como material didático, ele pega base da Lodenir Karnopp, que é uma autora referência na área de literatura surda, ela trabalha também na UFSC e a gente também tem utilizado os materiais dela. Eu, [Henrique], uso mais essa abordagem da literatura surda que a gente tem criado assim, de criações próprias, dessa abordagem da UFSC, diferente desses materiais de tradução ou de adaptação. A gente tem feito criações próprias, têm preferido contações de histórias, piadas, poesias, enfim, esses materiais nossos. (ENTREVISTA, HENRIQUE, 20/05/2021).

O entrevistado evidencia, ao mesmo tempo, a importância do uso da literatura surda para o ensino de Libras, o seu interesse e engajamento em pesquisas nesse campo e, também, a escassez de materiais que proporcionam suporte a esse ensino. Henrique atuou como instrutor de Libras para crianças surdas em uma Rede Municipal de Ensino, nos anos iniciais do Ensino Fundamental, e, quando atuou, não tinha acesso às produções literárias em Libras, o que, segundo ele, certamente poderia ser um ganho para a sua atuação e para o aprendizado dos alunos. Por essa razão, ao considerar as necessidades didáticas e a fruição proporcionada, passou a desenvolver materiais. O contato com outros surdos, conforme demonstra em seu relato, pareceu fundamental para que estratégias metodológicas de trabalho fossem desenvolvidas, bem como a troca de experiências entre projetos que tematizam a Literatura Surda. Conforme destaca Skliar (1999), é interessante quando é criado um reconhecimento político da surdez, como

9. A Libras é uma língua complexa e sistematizada. Os seus itens lexicais são organizados/descritos por meio de cinco parâmetros: configuração de mãos; ponto ou local de articulação; movimento; orientação ou direcionalidade; e expressão facial ou corporal. 
diferença, fazendo com que essa perspectiva contribua para pressupostos e projetos a serem assumidos em debates sobre o ensino.

\subsection{Aproximações e distanciamentos entre as trajetórias}

A Literatura Surda, por meio de "histórias contadas em línguas de sinais por pessoas surdas apresenta uma tradição próxima a culturas que transmitem suas histórias oral e presencialmente" (KARNOPP; HESSEL, 2009, p. 134), produzindo uma socialização possibilitada pela memória da comunidade. As entrevistas com os dois professores surdos, Luana e Henrique, mostram um cenário já evidenciado por autores que defendem a importância da educação bilíngue:

Percebemos que as turmas de surdos e com surdos são bem distintas. Enquanto na turma de surdos há uma interação da turma com um único grupo - o que pode ser explicado pela identificação linguística e cultural -, nas turmas com surdos há uma clara divisão entre surdos e ouvintes, sendo que, na maioria dos casos, os grupos não se misturam, salvo raríssimas ocasiões, muitas vezes, impostas pelos professores (RODRIGUES, 2018, p. 103).

As percepções sobre o processo de escolarização dos surdos, ressaltadas por Rodrigues (2018), marcam um cenário em que a produção literária de surdos coloca o uso da Libras em centralidade, o que permite a esses professores atuarem politicamente no processo de construção identitária.

Os processos de apropriação leitora revelam-se, no entanto, diferentes nos dois percursos aqui relatados, indicando, conforme previsto, variações geracionais que sinalizam condições de produção e de circulação de diferentes formas de literatura, inclusive com posicionamentos autorais também distintos. Esse posicionamento não vem acompanhado de um juízo de valor, exatamente porque temos o postulado de que as práticas de letramento são situadas no tempo e no espaço. Cada um a seu modo construiu essa identidade de pertencimento, com maiores ou menores aproximações a um modelo demandado pela esfera escolar, já que ambos se apresentam como professores que vivenciam práticas sociais de letramento literário marcadas pela pluralidade.

\section{CONSIDERAÇÕES FINAIS}

Neste artigo, buscamos traçar reflexões acerca dos percursos trilhados por dois professores surdos, de diferentes gerações: Luana, com aproximadamente 50 anos, e Henrique, com pouco mais de 30 anos, buscando compreender como suas experiências influenciam no trabalho atualmente desenvolvido por eles. Apesar de trazerem experiências e repertórios distintos, os relatos dos participantes evidenciam traços comuns e recorrentes, quando se enfoca a educação de surdos em nosso país. Mesmo com políticas que reconheceram a Libras e o bilinguismo dos surdos, desde o início dos anos 2000 (BRASIL, 2002), como resultado de lutas da comunidade surda, a busca por reconhecimento e visibilidade persiste.

Procurando compreender como se deu a formação leitora em ambos os casos, evidenciamos a importância da literatura surda, que desponta em diferentes vias - materiais impressos e vídeos veiculados com o auxílio da tecnologia. Luana e Henrique ressaltaram a utilização da leitura surda no processo de aquisição da Libras, com seus alunos, destacando, inclusive, que esse uso é perpassado pela apropriação linguística, mas traz em seu bojo uma discussão mais ampla, que está articulada ao entendimento da surdez como diferença. Isso implica saber que, como língua, a Libras é composta por aspectos sociais, culturais e identitários, diretamente relacionados à forma como os surdos se expressam e se posicionam, enquanto agentes sociais. Por outro lado, ao pensar nos efeitos políticos da visibilidade trazida pela adjetivação 'surda', endossamos a lição relatada por Maria Teresa Andrueto (2012, p. 75): "Foi a lição de que mais me lembro: descobrir que a literatura não é necessariamente o lugar onde encontrar o igual, às vezes é a janela para se debruçar sobre o diferente".

Em um contexto contemporâneo de novas tecnologias, a socialização de artefatos culturais que estimulam a produção e circulação de literatura constitui um fator positivo de ampliação de repertórios e indica, principalmente, um redimensionamento do letramento literário, com o enfraquecimento de uma visão utilitarista que posiciona a literatura surda para além de uma simples adjetivação. Nessa direção, vislumbram-se processos educativos mais qualificados que reconhecem a Libras inserida, de fato, em práticas sociais de letramento que neutralizam funções pedagógicas tradicionalmente preconizadas pelos usos escolarizados. 


\section{REFERÊNCIAS}

ALMEIDA, M. (2018). Blog Escrevendo o Futuro. Slam do corpo. Disponível em: https://www.escrevendoofuturo.org.br/blog/ literatura-em-movimento/poetas-do-corpo-slam-mostra-a-voz-dos-surdos/. Acesso em: 25 out. 2021.

ANDRUETTO, M. T. (2012). Por uma literatura sem adjetivos. São Paulo: Ed. Pulo do Gato.

BRASIL. (2002). Lei no 10.436, de 24 de abril de 2002. Dispõe sobre a Língua Brasileira de Sinais - Libras e dá outras providências. Brasília, Casa Civil.

BRASIL. (2005). Decreto no 5626, de 22 de dezembro de 2005. Regulamenta a Lei no 10.436, de 24 de abril de 2002, que dispõe sobre a Língua Brasileira de Sinais - Libras, e o art. 18 da Lei no 10.098, de 19 de dezembro de 2000. Brasília, Casa Civil.

BRASIL. (2014). Plano Nacional de Educação 2014-2024. Brasília: Edições Câmara.

BRASIL. (2015). Lei no 13.146, de o6 de julho de 2015. Institui a Lei Brasileira de Inclusão da Pessoa com Deficiência (Estatuto da Pessoa com Deficiência).

BASSO, S. P. S.; CAPELLINI, V. L. M. F. (2012). Material didático para alunos surdos: a literatura infantil em Libras. Revista Eletrônica de Educação, v. 6, n. 2, nov. Relatos de Experiência, p. 491-512.

BRITO, F. B. de. (2013). O movimento social surdo e a campanba pela oficialização da língua brasileira de sinais. Doutorado em Educação. São Paulo: Universidade de São Paulo.

CAMPEllO, A. R. e S.; CASTRO, N. P. de. (2003). As Aventuras de Pinóquio em Lingua de Sinais/Português. Coleção Clássicos da Literatura em Libras-Português (infanto-juvenil). Petrópolis: Editora Arara Azul.

CAVALCANTI, M. C. (1999). Estudos sobre educação bilíngue e escolarização em contextos de minorias linguísticas no Brasil. D.E.L.T.A., vol. 15, n. especial, p. 385-417.

COSSON, R. (2006). Letramento Literário: teoria e prática. São Paulo: Contexto.

COSTA, J. M. da. (2020). Ensino de metáforas em língua portuguesa para surdos bilingues Libras-português. 2020. 165 f. Tese (Doutorado em Estudos Linguísticos) - Faculdade de Letras, Universidade Federal de Minas Gerais, Belo Horizonte.

FINNEGAN, R. (2015). Where is language? An antropologist's questions on language, literature and performance. London: Bloomsbury.

GURGEL, L. G.; KARNOPP, L. B. (2015). Narrativas sobre a educação literária bilíngue na prática pedagógica com alunos surdos. Revista Reflexão e Ação, Santa Cruz do Sul, v. 23, n. 3, p. 261-280.

INSTITUTO NACIONAL DE EDUCAÇÃO DE SURDOS INES. (2012). Chapeuzinbo Vermelho em Libras. Rio de Janeiro: INES.

KARNOPP, L. B.; HESSEL, C. (2009). Metodologia da Literatura Surda. Universidade Federal de Santa Catarina, Licenciatura em Letras-Libras na Modalidade a Distância, Florianópolis.

KARNOPP, L. B. (2010). Produções culturais de surdos: análise da literatura surda. Cadernos de Educação, FaE/PPGE/UFPel, Pelotas [36]: 155-174. Disponível em: https://periodicos.ufpel.edu.br/ojs2/index.php/caduc/article/viewFile/1605/1488. Acesso em: 30 mai. 2021.

MAHER, T. M. (1997). O Dizer do sujeito bilíngue: aportes da sociolinguística. Anais do Seminário Desafios e possibilidades na educação bilíngue para surdos. Rio de Janeiro: Instituto Nacional de Educação de Surdos, p. 20-26.

MARCUSCHI, L. A. (1999). Análise da Conversação. 5.ed. São Paulo: Ática.

MEGALE, A. (2018). Educação bilíngue de línguas de prestígio no Brasil: uma análise dos documentos oficiais. The Especialist. Volume 39, número 2, p. 1-17. 
MOURÃO, C. H. N. (2016). Literatura surda: experiência das mãos literárias. 2016. Tese (Doutorado em Educação) - Programa de Pós-Graduação em Educação, Universidade Federal do Rio Grande do Sul, Porto Alegre.

NEVES, C. A. de B. (2017). Slams - letramentos literários de reexistência ao/no mundo contemporâneo. Linba D’Água (Online), São Paulo, v. 30, n. 2, p. 92-112.

OliveIRA, M. A. A. de; OliveIRA, M. L. M. B. de; CARVALHO, O. V. G. de. (2008). Um mistério a resolver: o mundo das bocas mexedeiras. Rio de Janeiro: LSB Vídeos.

PAULINO, G. (2010). Saramago na Pedagogia: Leitura literária e seu uso docente. In: MARINHO, M.; CARVALHO, G. Cultura escrita e letramento. Belo Horizonte: Ed. UFMG, p. 404-16.

PIMENTA, N. (1999). Literatura Em LSB. Rio de Janeiro: LSB Vídeos.

QUADROS, R. (1997). Educação de Surdos: a aquisição da linguagem. Porto Alegre: Artmed.

RAMOS, C. R. (2002). Iracema em Libras. Coleção Clássicos da Literatura em Libras-Português (infanto-juvenil). Petrópolis: Editora Arara Azul.

REZENDE, R. C. F. de. (2020). Despetacular Festival. Anais do primeiro Despetacular Festival. Brasília.

RODRIGUES, C. H. (2018). Reflexões sobre o ensino aprendizagem em turmas de surdos e com surdos. In.: SILVA, I. R.; SILVA, M. P. M. Letramento na Diversidade: surdos aprendendo a ler/escrever. Campinas, São Paulo: Mercado de Letras.

SILVA, G. M. da. (2014). O processo de ensino-aprendizagem da leitura em uma turma de alunos surdos: uma análise das interações mediadas pela Libras. RBLA, Belo Horizonte, v. 14, n. 4, p. 905-934.

SILVEIRA, C. H.; ROSA, F.; KARNOPP, L. (2011). Cinderela Surda. Canoas/RS: ULBRA, 3 ed.

SKLIAR, C. (1999) A localização política da educação bilíngue para surdos. In.: SKLIAR, C. (org.). Atualidade da Educação Bilíngue para Surdos: processos e projetos. Porto Alegre: Mediação, v. 1, p. 7-14.

STREET, B. V. (2014). Letramentos sociais. Abordagens críticas do letramento no desenvolvimento, na etnografia e na educação. São Paulo: Parábola.

SUTTON-SPENCE, R. et al. (2020). Antologias literárias em Libras. Fórum Linguístico, v. 17, p. 5505-5525.

SUTTON-SPENCE, R. (2021). Literatura em Libras. Petrópolis: Editora Arara Azul.

UNIVERSIDADE FEDERAL DE MINAS GERAIS. (2021). Faculdade de Letras. Projeto Mãos Literárias. Disponível em: http:// www.letras.ufmg.br/maosliterarias/. Acesso em: 25 out. 2021.

Recebido: $21 / 7 / 2021$

Aceito: 21/10/2021

Publicado: 26/10/2021 